\title{
A GIFT OF PAIN
}

In search of a cure.

BY V. G. CAMPEN

A woman lies on the stretcher, her body rigid with pain. She watches as I manoeuvre my portable console into the curtained cubicle, keeping her eyes open until the first electrode touches her forehead.

"It's my belly that hurts," she says. "Not my head."

I respond with standardized explanations, verbiage recommended by the Association of Neural Audit Technicians. "The nerves in your body transmit sensory signals, but your brain interprets them. By monitoring your sensations I can help to make a diagnosis." She turns her head away in a dismissive movement.

"I've been trained to recognize hundreds of sensory patterns," I say, careful to avoid the word 'pain'. I remain professionally detached, neither validating nor questioning the patient, trying to minimize the confounding effect of my presence. Simply applying electrodes can soothe or inflame, depending on the patient's history and emotional state.

"It really does hurt," she whispers. "A lot."

"I document only the quality of sensations, not the intensity," I say. I'm distracted, busy stretching a baby-blue cap over my head, repositioning it until I hear the click of the magnets woven into the fabric as they mate with the metal implants in my skull. A thick umbilicus of braided wire hangs from the back of the cap. I breathe deeply and prepare for the fog - technician's slang for the disorientation that occurs when synchronizing with a patient; a wave of confusion and nausea, like waking up alone and ill in a foreign country.

I plug into the console and as the fog clears, I quite literally feel my patient's pain. Knowing I can escape by disconnecting the wires makes it bearable. I sift through the input from individual electrodes, examine various combinations, and ascribe her pain to appendicitis. It's subcostal, an atypical location, which explains why it wasn't picked up during the physical examination. And although ethically I can't report on the

\section{$\rightarrow$ NATURE.COM}

Follow Futures:

3. @NatureFutures

f go.nature.com/mtoodm intensity, privately I rate the pain an eight out of ten.

"I swear it's real," she says. "I didn't

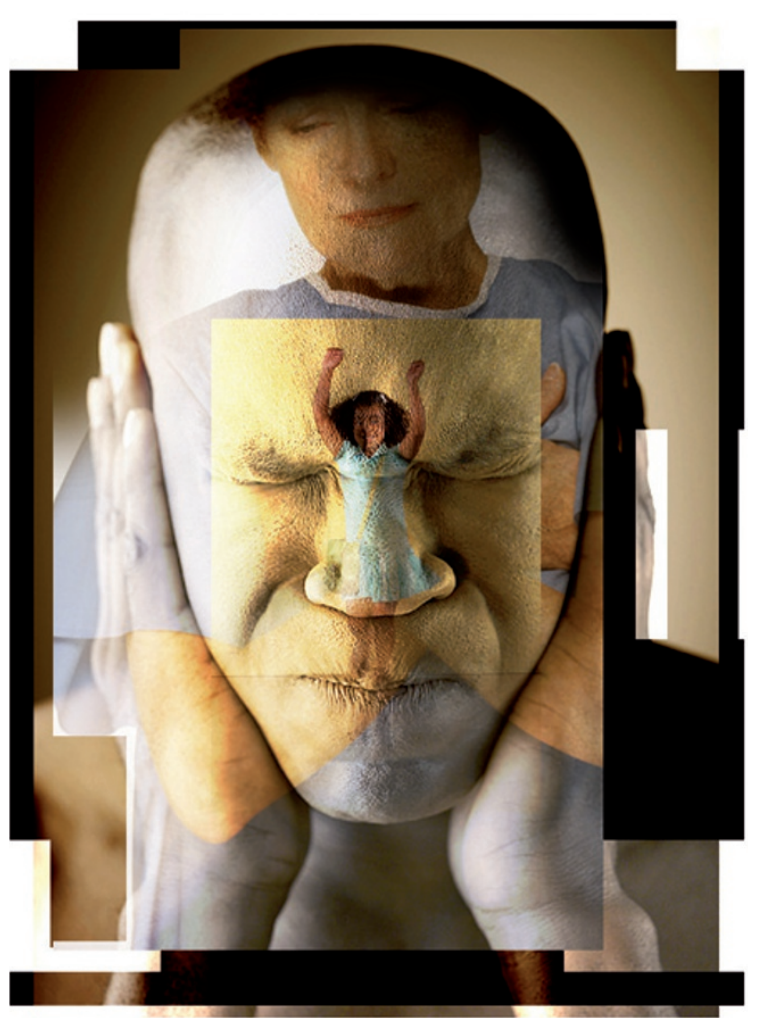

the distinctive rolling gait caused by the prosthetic blades below his knees. For some reason, people who suffer phantom limb pain tend to make excellent NATs, and the roadside bomb that tore Tanner apart and killed the others in his patrol prepared him well.

Usually I enjoy working with kids, the purity of their pain is refreshing. And yes, I know that sounds horrible. It's not something I'd say to the intern, who still has an outsider's prurient interest in NATs, undecided whether we're sadists who enjoy knowing another is in pain or masochists who enjoy feeling it. But I'm confident that each fresh-faced intern understands nociceptors and neural pathways, knows the proper use of analgesics and will learn to recognize the many forms of pain.

My therapist has asked gently, repeatedly, if my career is a way of punishing myself. I try to explain that my work isn't punishment, it's a relief. And it pays, unlike alcohol or narcotic abuse, and I've sampled both.

Here is the truth of it. My truth, at least. Physical pain pushes out the unnameable pain. The pain that has not

want to come to the hospital, but it hurts so bad..."

"I believe you," I say, breaking all the rules, and tears spill onto her cheeks. "I'll find your doctor and personally give my report." I enter a brief note into her medical e-record and the system adds its automatic time stamp: midnight.

"Hey Jan, what are you doing this weekend?" Tanner, my friend and the other NAT on duty, greets me in the break room. "We're having a picnic at the lake on Sunday. Why don't you drive up with me and Keisha?" Tanner knows that Sunday is the tenth anniversary of my daughter's death.

"I'm taking a weekend shift," I say, and he nods, understanding in full.

One of the new interns, the tall skinny one, leans in through the break-room door, his arms spread to either side of the doorframe. With his baggy white coat splayed open he reminds me of a crane about to take flight.

"Um, hi," he says, looking from Tanner to me. "There's a two-year-old in bay nine, a car accident..."

"I'll take the kid," Tanner says. He puts his hand on my shoulder and walks out with been mapped to any region of the brain but lives in every breath. You don't need to know how my daughter died. All you need to know is that I was drinking, and she died.

I stop at the lift where a trolley bearing my midnight patient waits. She lifts her hand in greeting.

"It's appendicitis," she says. "They're admitting me for surgery." Her body is no longer contorted, probably due to pain killers, possibly aided by the comfort of a diagnosis. She grasps my hand as the lift door opens. "Thank you."

In ancient times, men known as sin-eaters would, for a few coins, eat a meal off a dying man's chest in a ritual consumption of his sins. Perhaps we are pain-eaters, no more able to conquer pain than a sin-eater could wash away sins, but giving a sliver of comfort nonetheless.

"Thank you," I say as the trolley rolls forward, pulling my patient's hand from my grasp. -

V. G. Campen, after decades of reading, recently began writing fiction. During the day she works as a patent attorney in the biotech field. 